\title{
A Polygalacturonase-Inhibiting Protein from Grapevine Reduces the Symptoms of the Endopolygalacturonase BcPG2 from Botrytis cinerea in Nicotiana benthamiana Leaves Without Any Evidence for In Vitro Interaction
}

\author{
Dirk A. Joubert, ${ }^{1}$ Ilona Kars, ${ }^{2}$ Lia Wagemakers, ${ }^{2}$ Carl Bergmann, ${ }^{3}$ Gabré Kemp,,${ }^{4}$ Melané A. Vivier, ${ }^{1}$ and \\ Jan A. L. van Kan² \\ ${ }^{1}$ Institute for Wine Biotechnology, Department of Viticulture and Oenology, Stellenbosch University, Stellenbosch, 7600, \\ South Africa; ${ }^{2}$ Wageningen University, Laboratory of Phytopathology, Binnenhaven 5, 6709 PD Wageningen, \\ The Netherlands; ${ }^{3}$ Complex Carbohydrate Research Center, University of Georgia, Athens 30602-4712, U.S.A.; \\ ${ }^{4}$ Department of Plant Sciences, University of the Free State, Bloemfontein 9300, South Africa
}

Submitted 13 July 2006. Accepted 15 November 2006.

\begin{abstract}
Six endopolygalacturonases from Botrytis cinerea (BcPG1 to BcPG6) as well as mutated forms of BcPG1 and BcPG2 were expressed transiently in leaves of Nicotiana benthamiana using agroinfiltration. Expression of BcPG1, BcPG2, BcPG4, BcPG5, and mutant BcPG1-D203A caused symptoms, whereas BcPG3, BcPG6, and mutant BcPG2-D192A caused no symptoms. Expression of BcPG2 caused the most severe symptoms, including wilting and necrosis. BcPG2 previously has been shown to be essential for $B$. cinerea virulence. The in vivo effect of this enzyme and the inhibition by a polygalacturonase-inhibiting protein (PGIP) was examined by coexpressing Bcpg2 and the Vvpgip1 gene from Vitis vinifera in $N$. benthamiana. Coinfiltration resulted in a substantial reduction of the symptoms inflicted by the activity of BcPG2 in planta, as evidenced by quantifying the variable chlorophyll fluorescence yield. In vitro, however, no interaction between pure VvPGIP1 and pure BcPG2 was detected. Specifically, VvPGIP1 neither inhibited BcPG2 activity nor altered the degradation profile of polygalacturonic acid by BcPG2. Furthermore, using surface plasmon resonance technology, no physical interaction between VvPGIP1 and BcPG2 was detected in vitro. The data suggest that the in planta environment provided a context to support the interaction between BcPG2 and VvPGIP1, leading to a reduction in symptom development, whereas neither of the in vitro assays detected any interaction between these proteins.
\end{abstract}

Additional keywords: in planta interaction, pectinase, transient expression.

Pectin is an important component in plant cell walls, and it is especially prevalent in primary cell walls and the middle lamella (Chapple and Carpita 1998). The importance of pectin

Corresponding author: J. A. L. van Kan; Telephone: 31317483126 ; Fax: 31317 483412; E-mail: jan.vankan@wur.nl

Current address of I. Kars: UMR CNRS/INRA, Castanet-Tolosan, France.

Current address of D. A. Joubert: CAMBIA, Canberra, Australia. for plant tissue architecture and cell integrity was illustrated by expressing pectinolytic enzymes of fungal origin in plants (Boudart et al. 2003; Capodicasa et al. 2004). Stable transgenic tobacco plants expressing an endopolygalacturonase (PG) from Aspergillus niger were stunted and showed anatomical alterations. Only transgenic plants containing low levels of enzyme activity could be recovered, presumably because high expression is lethal (Capodicasa et al. 2004). Transient Agrobacterium tumefaciens-mediated expression of a Colletotrichum lindemuthianum PG in tobacco resulted in tissue collapse and induction of necrosis (Boudart et al. 2003), confirming the usefulness of agroinfiltration to study in planta effects of PGs.

A wide variety of biotrophic and necrotrophic plant-pathogenic fungi produce pectinolytic enzymes during infection of their hosts (ten Have et al. 2002). Production of these enzymes facilitates the hydrolysis of pectin, paving the way for the pathogen to colonize the host tissue while, at the same time, providing products of pectin degradation which serve as nutrients. One of the pathogenic fungi for which the role of pectinases has been studied is Botrytis cinerea, the cause of gray mould on a wide range of plants (Kars and van Kan 2004). The fungus possesses at least six BcPG-encoding genes (Wubben et al. 1999), which are differentially expressed in planta, depending on host tissue and incubation conditions (ten Have et al. 2001). Functional analysis has demonstrated that at least BcPG1 and BcPG2 are very important for virulence (Kars et al. 2005; ten Have et al. 1998). These two enzymes, produced in pure form in a heterologous system, are able to cause rapid and massive maceration and tissue collapse when infiltrated in leaves of several plant species (Kars et al. 2005).

Plants have developed a mechanism to counteract the action of PGs by expressing proteins known as polygalacturonaseinhibiting proteins (PGIPs) that inhibit the activity of fungal PGs. These proteins are considered to contribute to resistance against pectinase-producing pathogenic fungi (De Lorenzo et al. 2001). PGIPs typically are cell wall bound, tissue specific, developmentally regulated, and inducible by various stimuli, including pathogen attack, wounding, salicylic acid, jasmonic acid, oligogalacturonides (OGAs), and cold treatment (Bergmann et al. 1994; De Lorenzo et al. 2001; Desiderio et al. 
1997; Devoto et al. 1998; Ferrari et al. 2003; Komjanc et al. 1999; Mahalingam et al. 1999; Stotz et al. 1994). The functional importance of PGIPs in plants is corroborated by the observation that PGIP genes are under positive evolutionary selection (Bishop 2005, Stotz et al. 2000). PGs and PGIPs interact in a stoichiometric 1:1 ratio. Most of the interaction and inhibition data available for PG:PGIP pairs has been generated from in vitro assays. A commonly accepted model for PGIP-mediated defense suggests a dual function for PGIPs (De Lorenzo et al. 2001). PGIP may inhibit the action of fungal PGs either by binding to the active cleft of the PG, thereby preventing binding of the ligand to the enzyme (Federici et al. 2001), or by binding to the opposite side of the PG molecule, preventing the conformational changes necessary for ligand binding (King et al. 2002). In vitro evidence also suggests that the inhibition of PGs results in the prolonged existence of medium-chained length OGAs that subsequently can activate plant defense responses (Cervone et al. 1989; Reymond et al. 1995).

Thus, the inhibition of fungal PGs by PGIP may slow down infection by limiting cell wall hydrolysis and maceration and, in doing so, allow time to activate multiple defense responses to counteract the pathogen. Both these properties have generated an interest in exploiting PGIPs as tools for enhancing plant resistance. Several articles have reported the overexpression of various PGIP encoding genes, mostly in heterologous systems. These studies include the overexpression of pear pgip in tomato (Powell et al. 2000) and Vitis vinifera (Agüero et al. 2005), bean pgip in tobacco (De Lorenzo and Ferrari, 2002), the Arabidopsis pgip genes in Arabidopsis (Ferrari et al. 2003), as well as the grapevine pgipl gene in tobacco (Joubert et al. 2006). In all cases, a reduction in disease symptoms was reported when such transgenic plants were infected with $B$. cinerea.

We examined the damage that individual BcPGs are able to inflict when transiently expressed by agroinfiltration. BcPG2 was the most destructive enzyme and, therefore, was studied in more detail by coexpressing a PGIP gene (Vvpgipl) from $V$. vinifera. In this study, we show that VvPGIP1 quantitatively reduces the symptoms caused by BcPG2 expression in planta. Surprisingly, in vitro studies could not provide any indication that the two proteins in pure form could interact under the conditions tested. The results suggest a complex in vivo interaction between the protein pair tested.

\section{RESULTS}

\section{Individual transiently expressed $B$. cinerea PGs cause different symptoms in planta.}

B. cinerea $\mathrm{PG}$ BcPG1, BcPG2, BcPG3, BcPG4, BcPG5, and BcPG6 were transiently expressed in Nicotiana benthamiana. A. tumefaciens cultures containing any of the six Bcpg gene constructs, either containing the native fungal signal peptide or a signal peptide from the tobacco PR1a protein, were infiltrated into $N$. benthamiana and symptom development was monitored. Intercellular washing fluid was collected from infiltrated leaves and PG activity was tested both in a qualitative polygalacturonic acid (PGA) plate assay and a quantitative reducing sugar assay.

Of the constructs carrying the full-length $\mathrm{BcPG}$ open reading frame (ORF), including its own fungal signal peptide, only the BcPG2 construct caused symptoms, visible as chlorotic and necrotic responses with some tissue collapse. These symptoms typically appeared only at 120 to $144 \mathrm{~h}$ postinfiltration (hpi).

With constructs carrying the tobacco PR1a signal peptide, the first symptoms generally were observed at 24 to 36 hpi of the A. tumefaciens cells, and they progressed in subsequent days. Three types of responses were observed (Fig. 1; Table 1).
BcPG2 caused necrosis and tissue collapse (Fig. 1A, close-up in C), whereas BcPG1 caused chlorosis (Fig. 1B) and the development of yellow or brown patches scattered over the infiltrated area of the leaf (Fig. 1D, close-up). BcPG4 and BcPG5 caused symptoms similar to BcPG1 (not shown), whereas the empty vector pMOG800 (Fig. 1A and B), BcPG3, and BcPG6 (not shown) caused no symptoms or, at most, mild chlorosis. PG activity was detected in the intercellular fluid extracted from BcPG2-expressing leaves (Fig. 1E) from 1 to 5 days after infiltration. PG activity in the intercellular fluid extracted from leaves infiltrated with A. tumefaciens carrying the other Bcpg constructs remained below detection level (not shown).

Transient expression experiments also were carried out with all BcPG constructs in $N$. tabacum and tomato. Transient expression of BcPGs in N. tabacum cultivars caused a mild chlorosis 5 to 7 days after infiltration; however, results were inconsistent between experiments. Tomato leaves showed significant chlorotic symptoms upon infiltration with A. tumefaciens cells carrying the empty vector and, thus, were excluded from further experiments.

\section{Enzyme activity is required}

for symptom development by BcPG2 but not BcPG1.

In order to determine whether symptoms inflicted by transient expression of BcPG1 and BcPG2 require enzyme activity, constructs were generated encoding enzymatically inactive forms of BcPG1 and BcPG2 by introducing a mutation in their active site (D203A and D192A, respectively). The BcPG2D192A mutant protein, produced in Pichia pastoris, lacks PG activity and is unable to cause symptoms in plant tissue upon infiltration (Kars et al. 2005). The mutation D203A in the $\mathrm{BcPG} 1$ protein is in the analogous position in the catalytic site. The wild-type and mutant constructs were transiently expressed in $N$. benthamiana as described above, and the symptoms and PG activity in the intercellular fluid were monitored. The mutant form BcPG2-D192A neither caused symptoms (Fig. 1F; Table 1) nor showed detectable PG activity in the intercellular fluid (IF) (not shown) in agreement with results of Kars and associates (2005). The mutant BcPG1-D203A construct caused chlorotic symptoms with scattered yellow or brown patches to a similar extent as the wild-type BcPG1 (Fig. 1G; Table 1). PG activity in the intercellular fluid of plants infiltrated with the BcPG1 and BcPG1-D203A constructs was below the detection level in both cases.

\section{Assessment of tissue damage by chlorophyll fluorescence measurements.}

The macroscopic tissue damage in $N$. benthamiana leaves was most prominent upon expression of BcPG2. The damage caused by this enzyme was assessed further by measuring the reduction in chlorophyll fluorescence yield following infiltration with A. tumefaciens cultures containing the Bcpg2 construct carrying the PR1a protein signal peptide. Leaves were infiltrated at different cell densities ranging from optical density at $600 \mathrm{~nm}\left(\mathrm{OD}_{600}\right)=0.6$ to 0.06 . The $\mathrm{Fv} / \mathrm{Fm}$ ratio, where $\mathrm{Fv}=$ variable fluorescence and $\mathrm{Fm}=$ maximal fluorescence, representing the efficiency of energy capture of PSII, was measured before infiltration as well as $24 \mathrm{hpi}$ and the $\Delta^{\mathrm{Fv}} / \mathrm{Fm}\left({ }^{\mathrm{Fv}} / \mathrm{Fm}\right.$ preinfiltration $-{ }^{\mathrm{Fv}} / \mathrm{Fm}$ postinfiltration) was determined (Fig. 2). The greater the $\Delta^{\mathrm{Fv}} / \mathrm{Fm}$, the larger the reduction in efficiency of nonphotochemical quenching due to damage to PSII, providing an in planta quantitative measurement of symptom development. The $\Delta^{\mathrm{Fv}} / \mathrm{Fm}$ increased when higher cell densities of A. tumefaciens, containing the Bcpg 2 construct, were infiltrated into the leaves (Fig. 2). This dose-dependent reaction confirmed that chlorophyll measurement provides a useful quantitative assessment for the damage caused by PG activity in vivo. 


\section{Coexpression of a $V$. vinifera PGIP reduces} damage inflicted by BcPG2.

BcPG2 was the only enzyme for which substantial levels of enzyme activity were detected upon transient expression (Fig. $1 \mathrm{E})$. The $V$. vinifera PGIP VvPGIP1 has been shown to differentially inhibit PGs from B. cinerea (Joubert et al. 2006). Ex- periments were conducted to determine whether VvPGIP1 could affect the damage caused by BcPG2 in planta. As controls, we included in the experiments the inactive mutant BcPG2-D192A construct as well as a construct encoding the apoplastic protein VvAMP1 from $V$. vinifera (A. de Beer and M. A. Vivier, unpublished), which has no known interaction

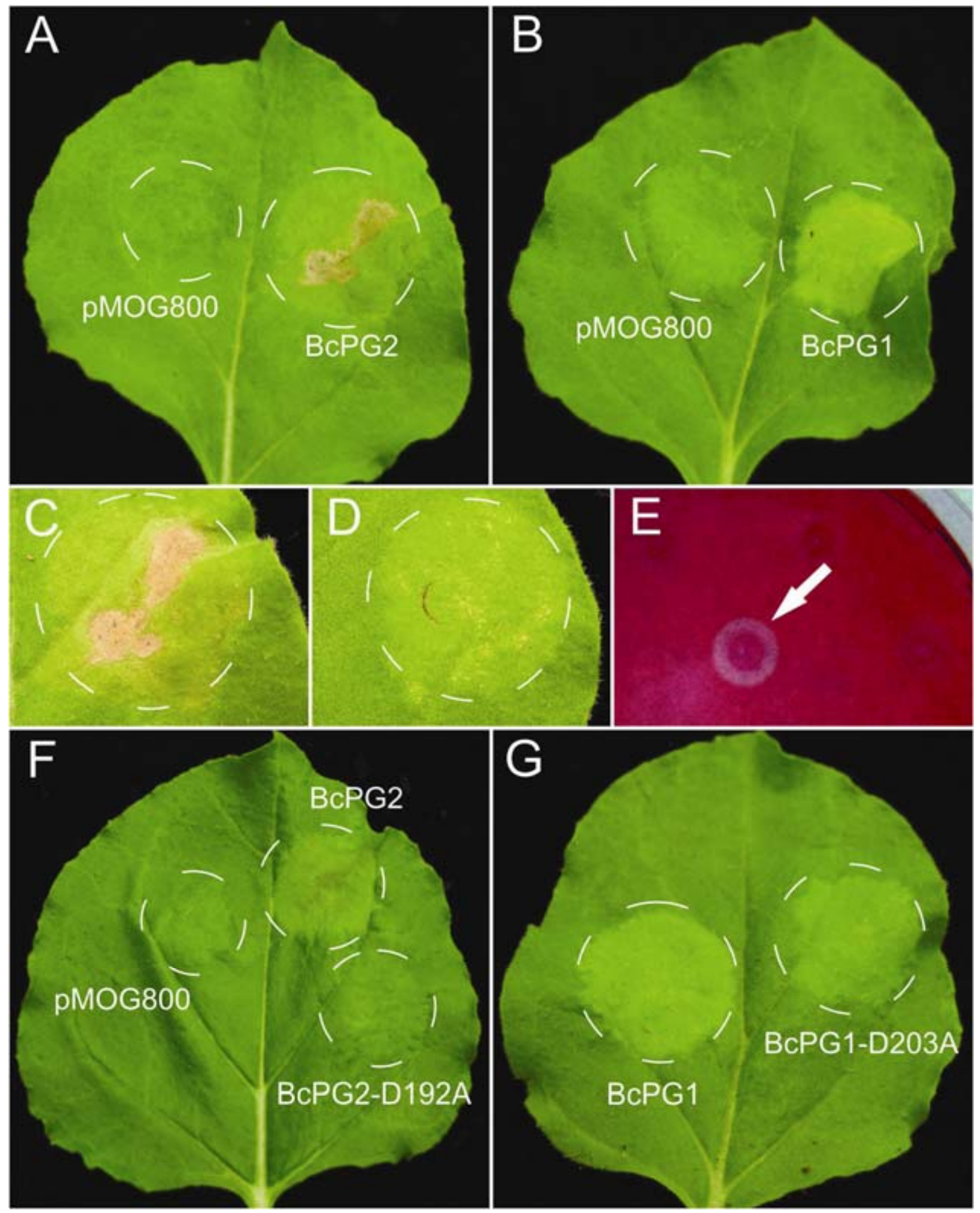

Fig. 1. Symptoms caused by transient expression of Botrytis cinerea endopolygalacturonases (BcPGs) in Nicotiana benthamiana. Zones where Agrobacterium tumefaciens cells were infiltrated are marked with a dotted white circle. A, BcPG2 caused necrosis, while empty vector pMOG800 caused no symptoms. B, BcPG1 caused chlorosis. C, Close-up of tissue collapse caused by BcPG2 expression. D, Close-up of yellow or brown tissue patches caused by BcPG1 expression. E, BcPG2 activity in intercellular fluid (arrow), visualized on polygalacturonic acid stained with ruthenium red $\mathbf{F}$, Inactive mutant BcPG2-D192A caused symptoms similar to the empty vector control. G, Inactive mutant BcPG1-D203A caused symptoms similar to the wild-type BcPG1. 
with either PGs or PGIPs. N. benthamiana leaves were infiltrated separately with the Bcpg2, Bcpg2-D192A, Vvpgip1, or Vvampl constructs, or coinfiltrated with various combinations of constructs in a 1:1 ratio. Northern analysis was performed, PG and PGIP activity was monitored in extracts from infiltrated leaves, and symptom development was scored 24 hpi (Fig. 3). Infiltration with $A$. tumefaciens cells containing the $B c p g 2$ construct, as well as coinfiltration of leaves with the $A$. tumefaciens cells containing Bcpg2 and the Bcpg2-D192A or Vvampl constructs, caused extensive wilting at 24 hpi. In contrast, leaves coinfiltrated with Bcpg2 and Vvpgipl displayed substantially less wilting (Fig. 3A). Leaves infiltrated with empty vectors, Vvpgip1, Vvampl, or Bcpg2-D192A alone or in combination (not shown) did not show any symptoms 24 hpi.

At 24 hpi, Bcpg2, Bcpg2-D192A, Vvampl, and Vvpgipl mRNAs were expressed in the infiltrated leaves (Fig. 3B). PG activity was detected in crude protein extracts from all leaves infiltrated with a functional Bcpg 2 construct and PG levels did not significantly differ between single and coinfiltration experiments (Fig. 3C). Inhibitory activity against Aspergillus niger AnPG-I could be detected in all leaves infiltrated with Vvpgipl alone or in combination with Vvampl and did not differ significantly (Fig. 3D). PGIP activity against AnPG-I in leaves coinfiltrated with the Vvpgipl and Bcpg2 constructs could not be determined due to the presence of BcPG2 activity in the extract. VvAMP1 activity in leaves infiltrated with the Vvampl construct was similar for single- and coinfiltration experiments (not shown). Coinfiltration of A. tumefaciens cells containing the $B c p g 2$ construct, with cells containing a pgipencoding gene isolated from the grapevine rootstock cv. Ramsey, encoding a protein with six polymorphic residues, gave results similar to those with the Vvpgipl gene (not shown).

The $\Delta^{\mathrm{Fv}} / \mathrm{Fm}$ values for leaves infiltrated with the single $B c p g 2$ construct as well as leaves coinfiltrated with the Bcpg 2 and Vvampl or Bcpg2-D192A constructs were significantly higher than the $\Delta^{\mathrm{Fv}} / \mathrm{Fm}$ values of leaves coinfiltrated with the Bcpg2 and Vvpgipl constructs (Fig. 3E). Leaves infiltrated with empty vectors, Vvpgip1, Vvamp1, Bcpg2-D192A alone, or in any combination thereof did not show any symptoms, and $\Delta^{\mathrm{Fv}} / \mathrm{Fm}$ values were $<0.05$ (Fig. 3E).

If VvPGIP1 and BcPG2 physically interact in a 1:1 ratio, one may predict that increasing the relative amount of $\mathrm{BcPG} 2$ would aggravate the symptoms, whereas increasing the relative amount of VvPGIP1 would not affect the symptoms. $N$. benthamiana leaves were infiltrated with A. tumefaciens cells containing the respective genes mixed in different Bcpg2:Vvpgip 1

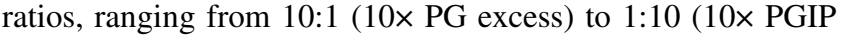
excess). After $24 \mathrm{~h}$, wilting was observed in leaves infiltrated with Bcpg2 and Vvpgipl in ratios of $10: 1$ and 5:1, whereas leaves infiltrated with ratios of $1: 1,1: 5$, and $1: 10$ appeared phenotypically normal at this point in time (not shown). Chlorophyll fluorescence $\left(\Delta^{\mathrm{Fv}} / \mathrm{Fm}\right)$ values were determined to assess the damage inflicted by $\mathrm{PG}$ action (Fig. 4). The $\Delta^{\mathrm{Fv}} / \mathrm{Fm}$ increased with higher levels of BcPG2; leaves infiltrated with a

Table 1. Symptoms on leaves of Nicotiana benthamiana observed after infiltration of transformed Agrobacterium tumefaciens cells ${ }^{\mathrm{a}}$

\begin{tabular}{ll}
\hline Expression construct & \multicolumn{1}{c}{ Symptoms } \\
\hline BcPG1 & Chlorosis; scattered yellow or brown spots \\
BcPG2 & Necrosis and tissue collapse \\
BcPG2 (native signal peptide) & Delayed necrosis, yellowing, and tissue collapse (only from 144 h onward) \\
BcPG3 & None \\
BcPG4 & Chlorosis; scattered spots \\
BcPG5 & Chlorosis; scattered spots \\
BcPG6 & None \\
BcPG2-D192A & None \\
BcPG1-D203A & Chlorosis; scattered spots \\
pMOG800 without BcPG & None \\
MMA buffer only & None \\
\hline
\end{tabular}

${ }^{a}$ All constructs contain a tobacco signal peptide unless otherwise indicated. Symptom development observed $48 \mathrm{~h}$ postinfiltration unless otherwise specified.

${ }^{\mathrm{b}}$ Buffer $=\mathrm{MgCl}_{2}$ at $10 \mathrm{mmol}$ liter ${ }^{-1}$ and MES at $10 \mathrm{mmol} \mathrm{liter}^{-1}$, pH 5.6 .

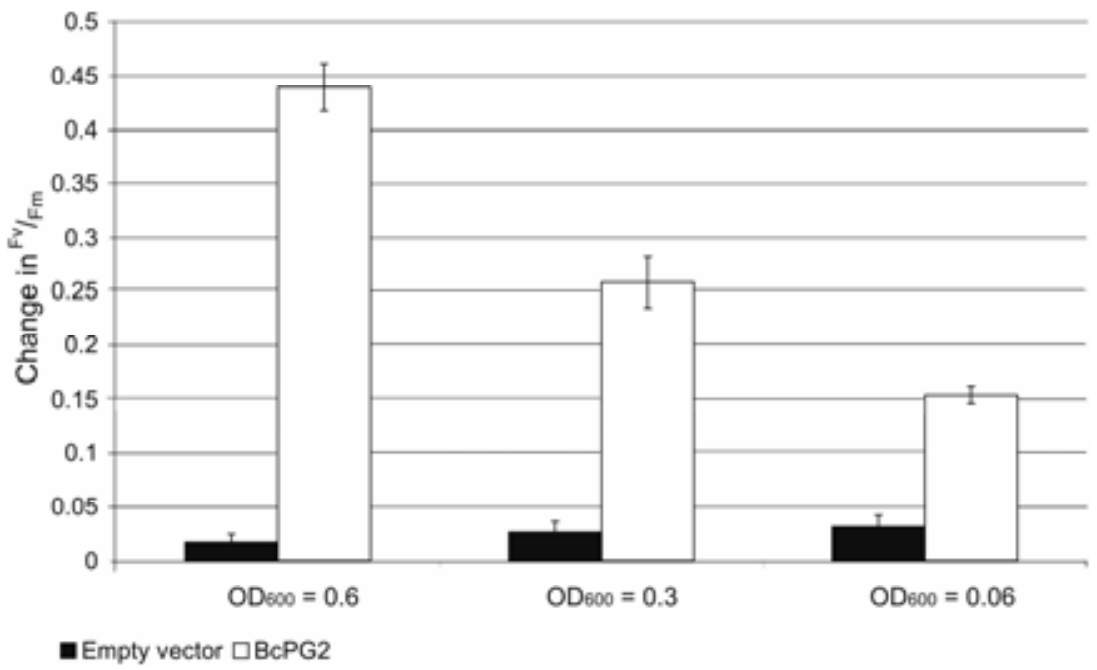

Fig. 2. Dosage-dependent effect of Botrytis cinerea endopolygalacturonase BcPG2 expression on the variable chlorophyll fluorescence ratio $\left({ }^{\mathrm{Fv}} / \mathrm{Fm}\right)$ in leaves of Nicotiana benthamiana. Agrobacterium tumefaciens containing the Bcpg2 construct carrying the PR1a signal peptide were infiltrated at different optical density at $600 \mathrm{~nm}\left(\mathrm{OD}_{600}\right)$ values $\left(0.6,0.3\right.$, and 0.06 , as indicated), and ${ }^{\mathrm{Fv}} / \mathrm{Fm}$ was monitored after 24 h. Closed bars represent the $\Delta^{\mathrm{Fv}} / \mathrm{Fm}$ in control leaves infiltrated with empty vectors (pART27 and pMOG800), whereas the open bars represent leaves infiltrated with Bcpg2 constructs. 
10-fold BcPG2 excess to VvPGIP1 showed a higher $\Delta^{\mathrm{Fv}} / \mathrm{Fm}$ compared with leaves infiltrated with a 5-fold BcPG2 excess and BcPG2:VvPGIP1 in a 1:1 ratio at 24 hpi. The $\Delta^{\mathrm{Fv}} / \mathrm{Fm}$ values of leaves infiltrated with a 1:1 ratio and a 5- or 10-fold VvPGIP1 excess to BcPG2 did not differ significantly between them, nor did they differ from the empty vector controls (Fig. 4).

\section{VvPGIP1 does not inhibit or physically interact with BcPG2 in vitro.}

The interaction between VvPGIP1 and BcPG2 in vitro was studied by analyzing PG inhibition (reducing sugar assays) and physical interaction (by plasmon resonance spectroscopy), as well as substrate profiling (anion exchange chromatography with amperometric detection). For these experiments, VvPGIP1 was used that was purified from transgenic tobacco overexpressing the Vvpgipl gene (Joubert et al. 2006). Tobacco leaves contained no detectable endogenous PGIP activity (not shown). The heterologously expressed VvPGIP1 showed no detectable differences in glycoslylation patterns or inhibition spectra compared with that of a PGIP purified from grapevine berries (Joubert et al. 2006). In all experiments, the Aspergillus niger PGI (AnPGI) was used as a positive control to verify that VvPGIP1 was active and the experimental conditions allowed for interaction. In reducing sugar assays using purified BcPG2 and VvPGIP1, no inhibition of BcPG2 activity was observed at any of the $\mathrm{pH}$ values tested (Fig. 5A), whereas AnPGI was readily inhibited by VvPGIP1 (Fig. 5B).

In order to test for the occurrence of physical interaction by plasmon resonance, purified VvPGIP1 was immobilized on a sensor chip and purified BcPG2 was applied to the chip at three $\mathrm{pH}$ values ranging from 4.2 to 5.0. No interaction between VvPGIP1 and BcPG2 could be detected, whereas VvPGIP1 interacted with AnPGI at pH 4.75 (Fig. 6). Results at pH 4.2 and 5.0 were essentially the same for both protein pairs (not shown).

PGIPs were reported to influence the product profiles of OGAs released from PGA by PG action (Cervone et al. 1987;

A

1

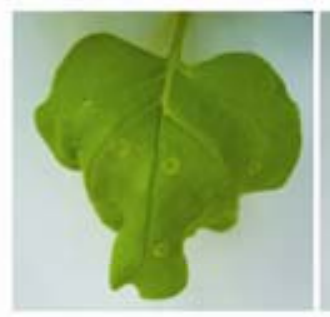

2

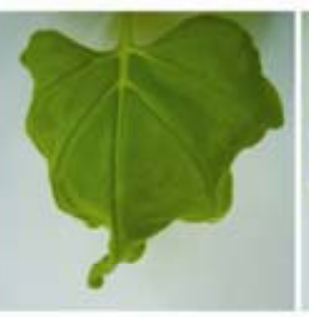

3

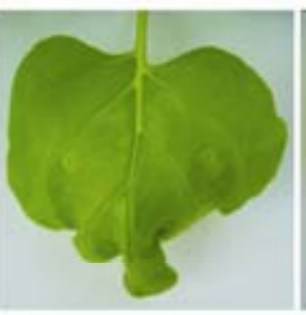

4

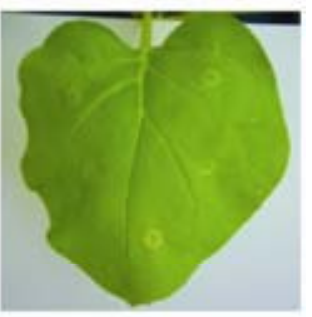

B

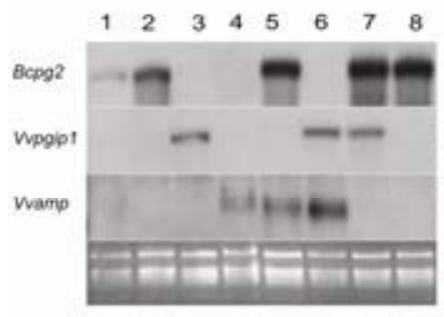

C

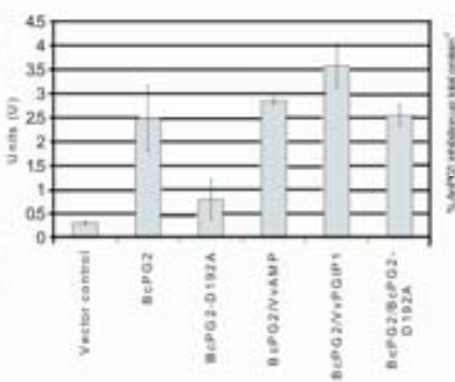

D

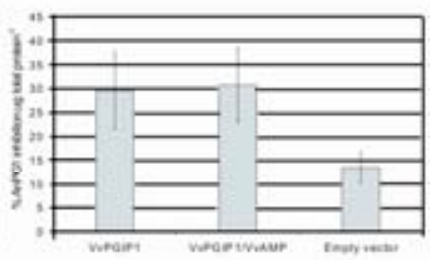

$\mathrm{E}$

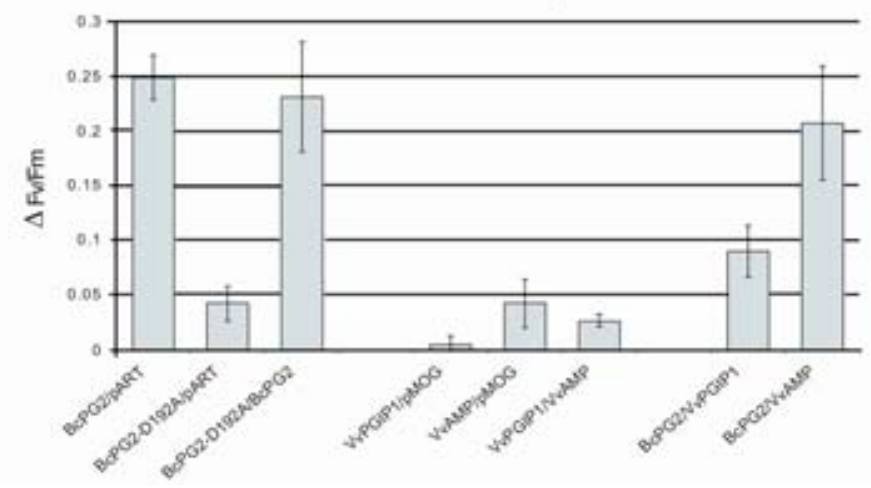

Fig. 3. Coexpression of Bcpg2 with Bcpg2-D192A, Vvamp1, or Vvpgip1 in Nicotiana benthamiana. Leaves were infiltrated with Agrobacterium tumefaciens strains carrying Vvpgip1, Vvamp1, and Bcpg2-D192A as well as the Bcpg2 constructs containing the PR1a signal peptide in a 1:1 ratio. A, Symptoms in leaves infiltrated with 1, Bcpg2 + pART27 (empty vector control); 2, Bcpg2 + Bcpg2-D192A; 3, Bcpg2 + Vvamp1; and 4, Bcpg2 + Vvpgip1 at 24 h postinfiltration (hpi). B, Northern blot analysis of Bcpg2, Bcpg2-D192A, Vvpgip1, and Vvamp1 expression in whole infiltrated leaves at 24 hpi. Blots were hybridized with probes specific for Bcpg2 (top panel), Vvpgip1 (middle panel), and Vvamp1 (bottom panel). Lane 1, Bcpg2; lane 2, Bcpg2-D192A; lane 3, Vvpgip1; lane 4, Vvamp1; lane 5, Bcpg2 + Vvamp1; lane 6, Vvpgip1 + Vvamp1; lane 7, Bcpg2 + Vvpgip1; and lane 8, Bcpg2 + Bcpg2-D192A. C, Endopolygalacturonase (PG) activity in crude protein extracts from leaves infiltrated with single constructs or combinations (as indicated below the bars) at 24 hpi, determined by agarose diffusion assay. D, Inhibition of AnPG1 by crude protein extracts isolated from leaves infiltrated with Vvpgip1, Vvpgip1 + Vvamp1, and empty vector, determined by agarose diffusion assay. E, Change in variable chlorophyll fluorescence yield $\left(\Delta^{\mathrm{Fv}} / \mathrm{Fm}\right)$ in $N$. benthamiana leaves infiltrated with combinations of Bcpg2, Bcpg2-D192A, Vvamp1, Vvpgip1, and empty vector (pART or pMOG), mixed in 1:1 ratios as indicated below the bars. 
Cook et al. 1999; Kemp et al. 2004). Degradation of PGA by BcPG2 in either the absence or presence of VvPGIP1 was investigated. No differences in OGA profiles were observed between PGA digested with BcPG2 in the absence or presence of VvPGIP1 (data not shown).

\section{DISCUSSION}

\section{Agrobacterium infiltration is suitable} to analyze the in planta effects of individual $B$. cinerea PGs and PG mutants.

The transient expression of BcPGs by A. tumefaciens-mediated infiltration of leaf material, first described for $C$. lindemuthianum ClPG1 (Boudart et al. 2003), enabled us to examine the extent of damage that individual $B$. cinerea $\mathrm{PGs}$ are able to cause in planta. As in the case of the ClPG1 (Boudart et al. 2003), a plant signal peptide was much more effective than the fungal signal peptide to obtain PG enzyme activity and symptoms. The PR1a signal peptide constructs consistently caused symptoms within $48 \mathrm{~h}$, whereas constructs with the native fungal signal peptide caused symptoms only several days later, if at all. The fungal signal peptide presumably conferred only low secreted protein production levels in N. benthamiana, consequently leading to less severe pectin degradation and delay of symptoms.

Transient expression enabled us to monitor the effects of BcPG enzymes that could not be produced in vitro in $P$. pastoris, such as BcPG5 (Kars et al. 2005). The latter enzyme was able to cause symptoms comparable in severity to BcPG1 and BcPG4. The method also allowed an examination of the effects of point mutations in individual enzymes, specifically mutations in the catalytic site that render the enzymes inactive without affecting their tertiary structure. The use of such mutants allows differentiation between plant tissue damage caused directly by enzymatic activity and damage resulting from defense responses following elicitor recognition, as best exemplified for BcPG1. The transient expression of BcPG1 in planta led to the development of chlorotic symptoms with yellow or brown patches of tissue, even when enzyme activity could not be detected in intercellular fluid. This may be due to the specific activity of BcPG1, which is substantially lower than that of other BcPGs (up to 90-fold lower than BcPG2) (Kars et al. 2005). The observation that expression of the inactive mutant protein BcPG1-D203A led to comparable symptom development in $N$. benthamiana suggests that BcPG1 can be recognized by the plant as an elicitor as previously concluded by Poinssot and associates (2003). However, it should be noted that the symptoms inflicted by BcPG1 were moderate and delayed compared with BcPG2. The latter enzyme was expressed to high activity levels in early stages and its expression resulted in massive cell collapse and tissue disintegration (Fig. $1 \mathrm{~A}$ and $\mathrm{C}$ ). Leaf tissue that expressed BcPG2 became brittle and easily fractured upon handling, possibly as a consequence of the rigidity of the cellulose network from which pectin had been removed. Expression of the inactive mutant protein BcPG2-D192A caused no symptoms, proving that enzyme activity is required for symptom development, as also was described for the $C$. lindemuthianum ClPG1 (Boudart et al. 2003). The dramatic effect of BcPG 2 action on tissue integrity probably overrules any elicitor responses that might be caused by recognition of BcPG1 or other BcPGs. The lack of symptoms triggered by infiltration with $A$. tumefaciens carrying Bcpg 3 or Bcpg 6 constructs probably is related to the fact that these enzymes do not cause any detectable damage in plant tissue, even when high activity levels are infiltrated in pure form into leaves (Kars et al. 2005).

The physiological effect of BcPG2 on leaves was quantified using a nondestructive and noninvasive assay technique. Chlorophyll fluorescence measurements demonstrated that the extent of damage in leaves expressing Bcpg2 increased with higher A. tumefaciens cell densities. Therefore, the chlorophyll fluorescence measurement was considered a suitable method to quantify tissue damage.

\section{In planta interaction of an individual BcPG and a PGIP upon transient coexpression.}

In spite of over 20 years of investigation, the role of PGIPs in plant defense responses is not fully understood. PGIPs differentially inhibit fungal PGs in vitro; however, little evidence is available to support the assumption that a successful in vitro interaction between a given PGIP-PG pair actually reflects the potential of this particular PGIP to increase resistance when

Change in $\mathrm{Fv} / \mathrm{Fm}$ ratios of $N$. benthamiana leaves infiltrated with combinations of vector, BcPG2 and VvPGIP1

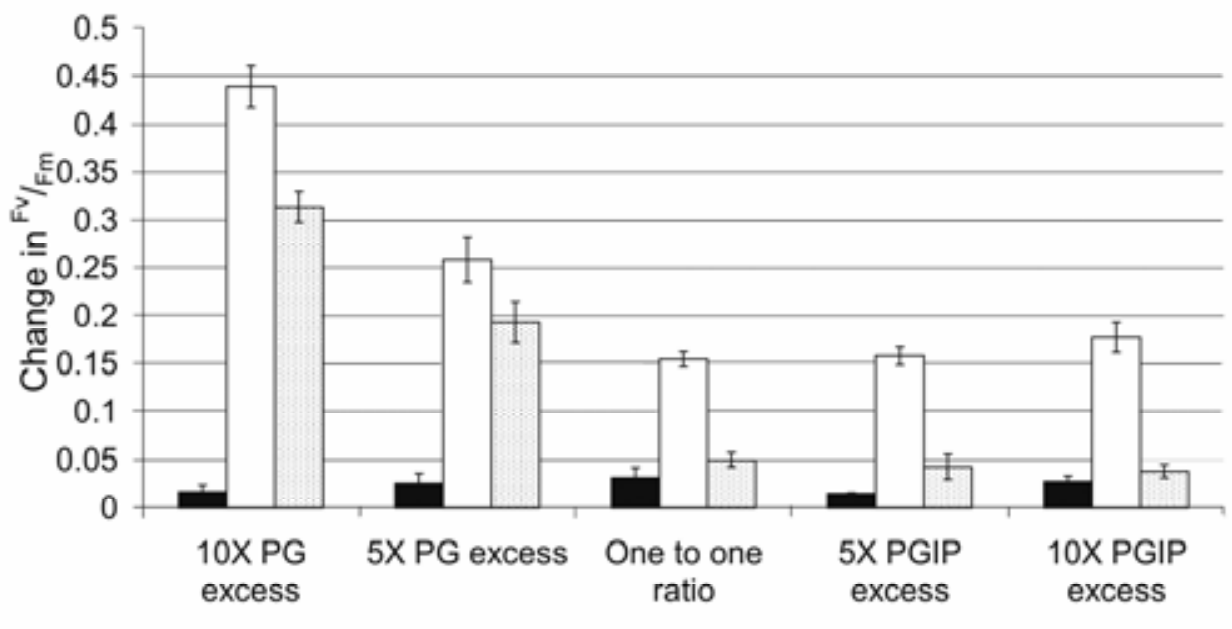

- pART/pMOG DpART/BCPG2 QVvPGIP1/BcPG2

Fig. 4. Effect on $\mathrm{Fv} / \mathrm{Fm}$ of overexpressing Botrytis cinerea endopolygalacturonase BcPG 2 alone or in combination with Vitis vinifera polygalacturonaseinhibiting protein VvPGIP1 in Nicotiana benthamiana. Leaves were infiltrated with different ratios of two empty vectors (closed bars), one empty vector + Bcpg2 (open bars), and Bcpg $2+$ Vvpgipl (stippled bars) and $\Delta^{\mathrm{Fv}} / \mathrm{Fm}$ in infiltrated leaves were measured after $24 \mathrm{~h}$ postinfiltration. 
expressed in planta. Overexpressing PGIPs in transgenic plants was shown to reduce $B$. cinerea disease symptoms (Agüero et al. 2005; De Lorenzo and Ferrari 2002; Ferrari et al. 2003; Powell et al. 2000). Also, VvPGIP1 reduced the susceptibility to B. cinerea when overexpressed in $N$. tabacum (Joubert et al. 2006). In view of the important role of BcPG2 in virulence of B. cinerea (Kars et al. 2005) and the observed increased resistance in PGIP-expressing plants, one would be tempted to ascribe this resistance (at least partially) to the inhibition of BcPG2 action by the PGIP. Coexpression of VvPGIP1 with $\mathrm{BcPG} 2$ indeed led to substantial symptom reduction, both visually and by chlorophyll fluorescence measurement, whereas no symptom reduction was observed when BcPG2 was coexpressed with a different secreted protein, such as BcPG2-D192A or VvAMP1. The extent of tissue damage in leaves expressing Bcpg2 increased with higher A. tumefaciens cell densities (Fig. 2); however, the damage was significantly reduced or even negated by coexpression of Vvpgipl (Fig. 3A and E). This result was corroborated by expressing various ratios of enzyme versus inhibitor (Fig. 4) and the results of this experiment provided confidence regarding the suitability of the test system to assess true interaction. Specifically, no appreciable differences in $\Delta^{\mathrm{Fv}} / \mathrm{Fm}$ values were observed in leaves infiltrated with $1: 1,1: 5$, or 1:10 Bcpg2:Vvpgipl ratios, strongly suggesting that a 1:1 stoichiometric interaction indeed occurs between VvPGIP1 and BcPG2, as generally is observed for the interaction of PGIP and PG in vitro (King et al. 2002).

\section{In vitro analyses detect no interaction between BcPG2 and VvPGIP1.}

Surprisingly, no physical interaction could be detected in vitro between VvPGIP1 and BcPG2, and VvPGIP1 did not alter the oligogalacturonide profile generated from PGA by BcPG2. Comprehensive methods were employed that normally are used to evaluate PG-PGIP interactions in vitro. The test systems all performed well as established with appropriate
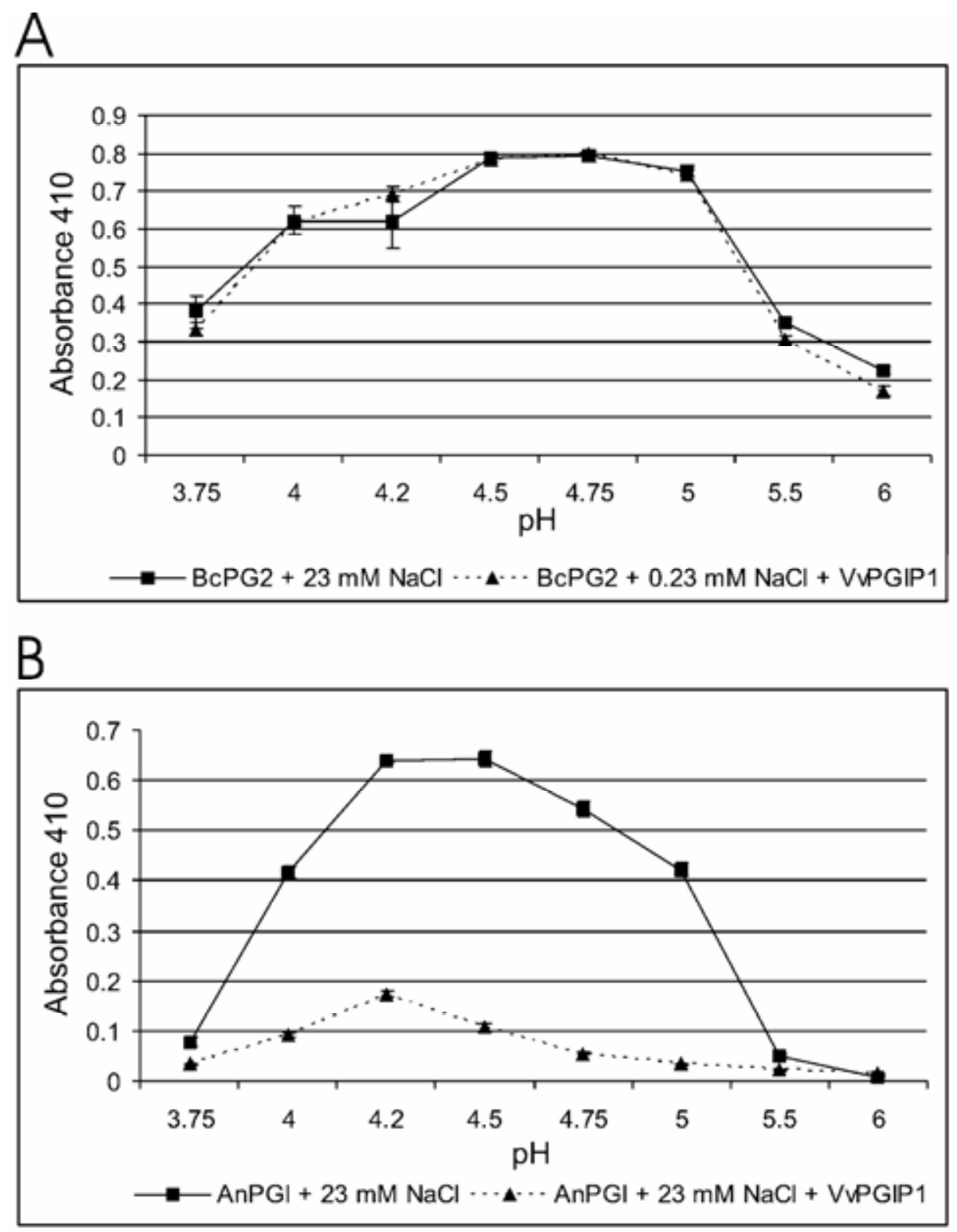

Fig. 5. Quantitation of endopolygalacturonase inhibition using colorimetric reducing sugar assays. A, Botrytis cinerea BcPG2 (approximately 50 ng) or B, Aspergillus niger AnPGI was incubated with polygalacturonic acid at a $\mathrm{pH}$ ranging from 3.75 to 6.0. The activity of AnPGI and BcPG2 alone is indicated by a solid line and squared data points. Activity of both enzymes in the presence of Vitis vinifera polygalacturonase-inhibiting protein (PGIP) VvPGIP1 (approximately $100 \mathrm{ng}$ ) is indicated by a dotted line and triangular data points. 
controls; however, the interaction between BcPG2 and VvPGIP1 that was observed in planta could not be demonstrated in vitro. BcPG2 appears to be a rather unusual enzyme because, thus far, it has not been possible to detect any in vitro inhibitors. Crude PGIP-containing cell wall extracts from eight other plants (lemon, leek, pepper, apple, bean, onion, cucumber, and pear), as well as purified PGIPs from bean, tomato, and pear, all were unable to inhibit pure BcPG2 in vitro to any detectable level under any experimental condition tested, even though these extracts did inhibit several other pure BcPG enzymes (G. H. Krooshof, C. Bergmann, R. Joosten, J. A. E. Benen, and J. A. L. van Kan, unpublished).

The present models for the interaction between PGIPs and PGs postulate that their interaction depends on structural requirements in both proteins (Bishop 2005; Federici et al. 2001; Leckie et al. 1999). It always has been considered that the most potent in vitro inhibitors would be the most attractive proteins to express in plants for achieving optimal resistance to fungal pathogens in biotechnology approaches. The results of the present study, however, suggest that the current working hypothesis for PGs and PGIPs may require refinement by considering the possibility for the occurrence of an in vivo interaction in the absence of any detectable in vitro interaction between the protein pair. The transient coexpression system would be a suitable tool to examine whether similar observations can be made for different PG:PGIP protein pairs.

Recent evidence was presented that bean PGIPs are able to interact with pectin (Spadoni et al. 2006). It remains to be established whether VvPGIP1 also can bind to pectin. If so, rather than truly directly inhibiting BcPG2, VvPGIP1 might, in fact, operate by shielding the most exposed and vulnerable positions in the pectin, thereby making the substrate less accessible to BcPG2. Such a substrate shielding mechanism was proposed for the AVR4 protein from the fungal pathogen Cladosporium fulvum, which has chitin-binding properties and can protect the fungal cell wall from attack by plant chitinases, presumably by preventing the hydrolase from getting access to the substrate (van den Burg et al. 2006). Future surface plasmon resonance experiments might unravel whether VvPGIP1 can interact with pectin and, thereby, protect the substrate from hydrolysis by BcPG2.

\section{MATERIALS AND METHODS}

Transient expression of $B$. cinerea PGs in $N$. benthamiana.

A. tumefaciens strain GV3101 was transformed by electroporation. Recombinant $A$. tumefaciens containing the binary vector pMOG800 (Honée et al. 1998) was used for transient expression of the B. cinerea PG genes Bcpg1, Bcpg2, Bcpg3, Bcpg4, Bcpg5, and Bcpg6. For each gene, two types of constructs were made: one containing the full-length ORF (including the native $B$. cinerea signal peptide) and one containing the sequence encoding the mature protein, preceded by a functional plant signal peptide sequence. The target genes were amplified with primers containing specific restriction sites for cloning purposes (Table 2). The amplified products were digested with the appropriate restriction enzymes and subsequently cloned into pAT1 or pAT2 (derivates of pFM10) (Honée et al. 1998). The sequences of the mature proteins were cloned in pAT2 in frame with the signal sequence of tobacco PR1a using SalI and SacII. The resulting construct subsequently was cloned into pMOG800 with XbaI and EcoRI. All inserts were verified by DNA sequence analysis (BaseClear, Leiden, The Netherlands). The empty pMOG800 vector was used as control. Transformed A. tumefaciens cells were grown as described by van der Hoorn and associates (2000), except that they were suspended in $\mathrm{MMA}\left(\mathrm{MgCl}_{2}\right.$ at $10 \mathrm{mmol}$ liter ${ }^{-1}$ and morpholineethanesulfonic acid at $10 \mathrm{mmol} \mathrm{liter}^{-1}$, $\mathrm{pH}$ 5.6), to a final $\mathrm{OD}_{600}=1.0$ prior to infiltration into $N$. benthamiana, using disposable syringes without needle.

\section{Coinfiltration of BcPG2 with VvPGIP1, BcPG2D192A, or VvAMP1 in N. benthamiana.}

Vvpgipl was amplified with primers containing SalI and $X b a I$ sites (Table 2), purified, and cloned into the XhoI and XbaI sites of the pGEM9Zf derivative, pART7 (Gleave 1992) in between the 35S CaMV promoter and nopaline synthase terminator elements. The Vvpgipl expression cassette subsequently was excised from pART7 with NotI and cloned into the binary vector pART27 (derived from pMON530) (Gleave 1992; Rogers et al. 1987).

A full-length cDNA of an antifungal peptide from $V$. vinifera (VvAMP1) that was identified in an expressed sequence tag database (TC69032) and cloned into pART27 was obtained from Abre de Beer (Institute for Wine Biotechnology, Stellenbosch University, South Africa). The VvAMP1 protein has been shown to be secreted to the apoplastic space when expressed in transgenic tobacco (A. de Beer, personal communication).

$N$. benthamiana plants were grown from seed in a peat moss mixture and maintained in a greenhouse at $26^{\circ} \mathrm{C}$ and $70 \%$ humidity under natural light. Eight-week-old N. benthamiana plants were used for infiltration experiments. A. tumefaciens infiltrations were done according to Wroblewski and associates (2005). The A. tumefaciens strain EHA105 (Hood et al. 1993) was used for all coinfiltrations and was trans-
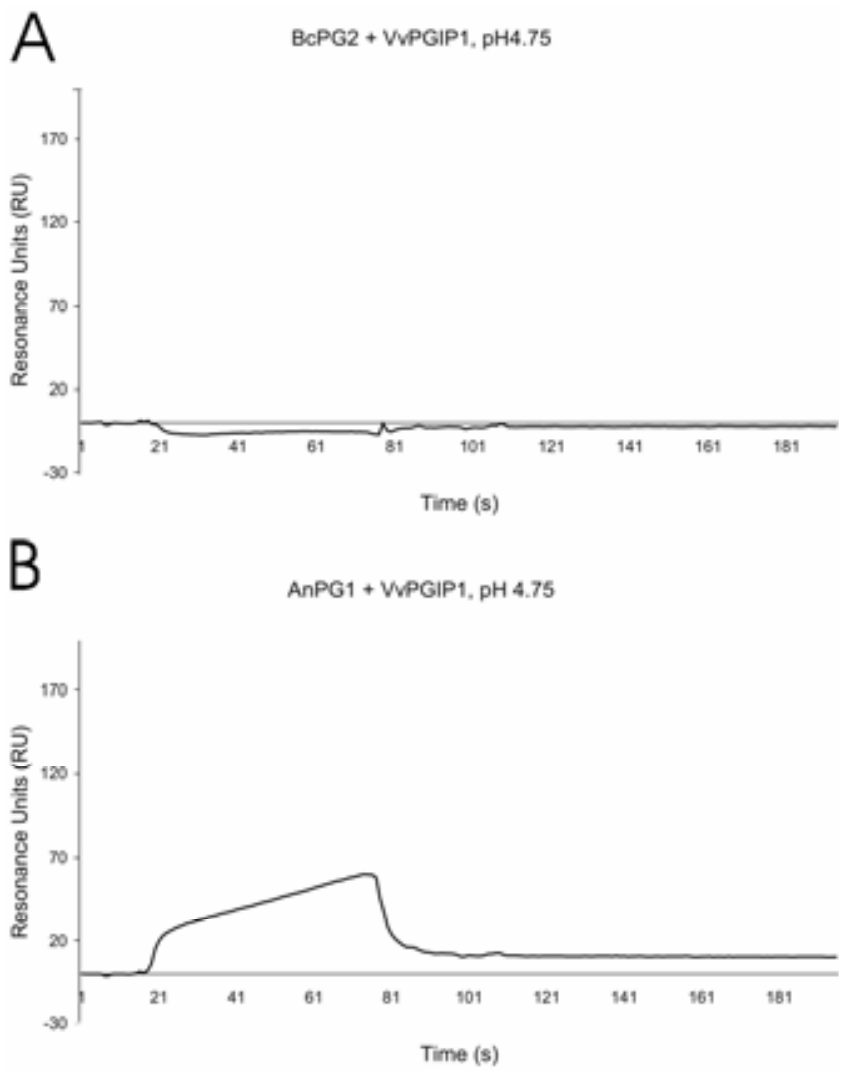

Fig. 6. Physical interaction at $\mathrm{pH} 4.75$ between pure Vitis vinifera polygalacturonase-inhibiting protein VvPGIP1 and $\mathbf{A}$, pure Botrytis cinerea endopolygalacturonase BcPG2 or $\mathbf{B}$, pure Aspergillus niger AnPGI measured by plasmon resonance. Association, dissociation, and regeneration phases were followed in real time and observed as a change in response units (RU). Binding was quantified by subtracting the flow cell sensorgram from the control flow cell sensorgram; 1,000 RU represent approximately $1 \mathrm{ng} \mathrm{mm}^{-2}$ of protein bound to the sensor chip surface. Results at $\mathrm{pH} 4.2$ and 5.0 were essentially the same for both protein pairs. 
formed with the appropriate constructs by electroporation. Unless otherwise stated, for coinfiltrations based on a 1:1 ratio, the cell densities of Agrobacterium cells carrying each construct were adjusted to $\mathrm{OD}_{600}=0.3$, therefore allowing for the total cell density of $\mathrm{OD}_{600}=0.6$. For the coinfiltration experiment where the effect of different ratios of VvPGIP1 to BcPG2 was compared (Fig. 4), the Agrobacterium cell densities were mixed in the ratios described in Table 3 . All infiltrations were done in triplicate using three separate leaves on the same plant. Infiltrated plants were maintained in a greenhouse at $26^{\circ} \mathrm{C}$ and $70 \%$ humidity under natural light until chlorophyll fluorescence measurements were taken or tissue collected for subsequent analysis.

\section{Activity assays.}

IFs were isolated from $N$. benthamiana leaves at 1 to 5 days after infiltration with A. tumefaciens cells, as described by de Wit and Spikman (1982). PG activity in IF was examined qualitatively by spotting a $2-\mu \mathrm{l}$ droplet of IF on agar plates containing 0.1\% (wt/vol) PGA, pH 4.2 (Sigma, Zwijndrecht, The Netherlands). After incubation at $30^{\circ} \mathrm{C}$ for $30 \mathrm{~min}$, the plates were stained with ruthenium red (Fluka, Zwijndrecht, The Netherlands). Enzyme activity appeared as a white spot in a red background.

Crude protein extracts from $N$. benthamiana leaves were isolated by freezing the leaves in liquid nitrogen and grinding the tissue with a mortar and pestle to a fine powder. Extraction buffer (20 mM sodium acetate, $\mathrm{pH}$ 5.2, for crude PG; $100 \mathrm{mM}$ phosphate buffer, $\mathrm{pH}$ 7.0, for AMP isolations; and $20 \mathrm{mM}$ sodium acetate, $1 \mathrm{M} \mathrm{NaCl}, \mathrm{pH} \mathrm{5.2,} \mathrm{for} \mathrm{crude} \mathrm{PGIP}$ isolations) was added to a final ratio of $2 \mathrm{ml}$ of buffer per $1 \mathrm{~g}$ of starting tissue. Tissue was ground further in extraction buffer to a fine homogenate and incubated on ice for $1 \mathrm{~h}$ with gentle shaking. The mixture was centrifuged at $15,000 \times g$ for $25 \mathrm{~min}$ at $4^{\circ} \mathrm{C}$ and the supernatant filtered through one layer of miracloth, aliquoted, and stored at $-20^{\circ} \mathrm{C}$. Protein concentration was determined according to Bradford (1976) using a Biorad protein assay kit (Biorad, Johannesburg, South Africa) and bovine serum albumin as a standard. PG activity from crude protein extracts was measured using an agarose diffusion assay as described by Taylor and Secor (1988) using $0.5 \%$ PGA as substrate at $\mathrm{pH}$ 4.2. One enzyme unit (U) is defined as the amount of enzyme necessary to increase the zone size by $1 \mathrm{~mm}^{2}$ over a period of $16 \mathrm{~h}$.

To determine VvPGIP1 activity in crude protein isolates, 1 $\mu \mathrm{g}$ of total protein was incubated with $10 \mathrm{ng}$ of purified AnPG1 for $16 \mathrm{~h}$ at $30^{\circ} \mathrm{C}$ using an agarose diffusion assay as described. VvPGIP1 activity was expressed as the percent reduction in clearing zone sizes effected by AnPG1 with crude VvPGIP1 compared with clearing zones sizes effected by AnPG1 alone.

VvPGIP1 was purified from transgenic tobacco overexpressing the Vvpgipl gene essentially as described by Favaron and associates (1994). The inhibition of AnPGI and BcPG2 by VvPGIP1 was assayed using reducing sugar assays with purified VvPGIP1. VvPGIP1 was incubated with AnPGI or BcPG2 and $0.025 \%$ PGA (Sigma), then buffered in $50 \mathrm{mM}$ sodium acetate with a $\mathrm{pH}$ ranging from 3.75 to 6.0 for $1 \mathrm{~h}$ at room temperature. The inhibition of AnPGI and BcPG2 by VvPGIP1 was quantified following incubation by spectrophotometrically $(410 \mathrm{~nm})$ measuring the decrease in the release of reducing sugars, using the p-hydroxybenzoic acid hydrazide procedure (York et al. 1985). PGA was included as control. In order to compensate for the possible influence of chromatography buffer gradient on the enzyme activity, equivalent amounts of salt were added to all assays. All assays were done in triplicate.

Table 3. Agrobacterium tumefaciens cell densities used for agro-infiltrations of Vvpgip1 and Bcpg2 carrying the PR1a signal peptide

\begin{tabular}{ll}
\hline pART:pMOG, pART:BcPG2, and VvPGIP1:BcPG2 & OD $_{\mathbf{6 0 0}}{ }^{\mathbf{a}}$ \\
\hline $1: 10$ & $0.06: 0.6$ \\
$1: 5$ & $0.06: 0.3$ \\
$1: 1$ & $0.06: 0.06$ \\
$5: 1$ & $0.3: 0.06$ \\
$10: 1$ & $0.6: 0.06$ \\
\hline
\end{tabular}

${ }^{a}$ Optical density at $600 \mathrm{~nm}$.

Table 2. Primers (forward and reverse) used to generate expression constructs

\begin{tabular}{|c|c|c|c|c|}
\hline Vector & Insert & Primer name & Primer sequence $\left(5^{\prime}-3^{\prime}\right)^{a}$ & Restriction site \\
\hline \multirow[t]{12}{*}{$\overline{\mathrm{pAT} 1}$} & Bcpg1 & $00-12$ & AGAGAGCCATGGTCAACTTCTCTCAATGG & NcoI \\
\hline & & $00-14$ & AGAGAGCCGCGGTTAACACTTGACACCAGATGGG & SacII \\
\hline & Bcpg2 & $00-1$ & CACTCACCATGGTTCATATCACAAGCC & NcoI \\
\hline & & $00-2$ & GAGAGCCGCGGTTAGCAAGAAGCTCCGGT & SacII \\
\hline & Bcpg3 & $00-9$ & 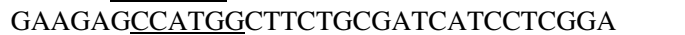 & NcoI \\
\hline & & $00-11$ & AGAGAGCCGCGGTTATGATGGGCATCCAG & SacII \\
\hline & Bcpg 4 & $00-15$ & AGAGAGCCATGGCTTCCACCAAGTCTATGGCAGCT & NcoI \\
\hline & & $00-17$ & AGAGAGCCGCGGTTAAGAGCAAGAACCAAC & SacII \\
\hline & Bcpg5 & $00-18$ & AGAGAGCCATGGTTAAGTTTTCTGCCTG & NcoI \\
\hline & & $00-20$ & AGAGAG $\overline{C C G C G G}$ CTACAAGGAACAAGAGAC & SacII \\
\hline & Bcpg6 & $00-21$ & GAGAGGCCATGGCTAAGAACTCTCAGATCTC & NcoI \\
\hline & & $00-23$ & GAGGAGCCGCGGTATGCGGGACAGCCAG & SacII \\
\hline \multirow[t]{12}{*}{ pAT2 } & Bcpg1 & $00-13$ & GAGAGA $\overline{\text { GTCGACGCGTGGTACCGCCTGTACCT }}$ & SalI \\
\hline & & $00-14$ & AGAGAGCCGCGGTTAACACTTGACACCAGATGGG & SacII \\
\hline & Bcpg2 & $00-3$ & GAGAGGTCGACGCGTGCTGGTTGCACATTC & SalI \\
\hline & & $00-2$ & GAGAGCCGCGGTTAGCAAGAAGCTCCGGT & SacII \\
\hline & Bcpg3 & $00-10$ & GAGAGAGTCGACCTGCGACAACCCAGACCATGA & SalI \\
\hline & & $00-11$ & AGAGAGCCGCGGTTATGATGGGCATCCAG & SacII \\
\hline & Bcpg4 & $00-16$ & AGAGAGCTCGAGGCGTGCCGCAACCTGT & XhoI \\
\hline & & $00-17$ & AGAGAGCCGCGGTTAAGAGCAAGAACCAAC & SacII \\
\hline & Bcpg5 & $00-19$ & AGAGAGGTCGACGCGAGCAACTACCTGCACT & SalI \\
\hline & & $00-20$ & AGAGAG $\overline{C C G C G G} C T A C A A G G A A C A A G A G A C$ & SacII \\
\hline & Bcpg6 & $00-22$ & GAGAGAGTCGACGCAAACAGCTTGTACTGCC & SalI \\
\hline & & $00-23$ & GAGGAGCCGCGGTATGCGGGACAGCCAG & SacII \\
\hline \multirow[t]{2}{*}{ pART7 } & Vvpgip1 & Pgips & GTCGACATGGAGACTTCAAAAC & SalI \\
\hline & & Pgipas & TCTAGAACTTGCAGCTCTGGAGTGGAG & XbaI \\
\hline
\end{tabular}

\footnotetext{
${ }^{\text {a }}$ Restriction sites introduced for cloning purposes are underlined.
} 
RNA extraction and Northern blot analysis.

Whole infiltrated leaves without the petiole were excised, and the tissue ground and subsequently used for both RNA extractions, according to Joubert and associates (2006). RNA was electrophoresed and blotted and blots were hybridized with probes containing the full-length ORFs of Vvampl, Bcpg2, and Vvpgip1. The probes were labeled and Northern blotting and detection were performed using the DIG system according to the DIG Application Manual for Filter Hybridization (Roche Diagnostics GmbH, Mannheim, Germany).

\section{Chlorophyll fluorescence parameters.}

The maximal photochemical yield of photosystem II was measured as variable chlorophyll fluorescent yield of dark adapted leaves (overnight) at room temperature with the following formula: $\mathrm{Fv} / \mathrm{Fm}=(\mathrm{Fm}-\mathrm{F} 0) / \mathrm{Fm}$, where $\mathrm{F} 0=$ initial fluorescence (Krause and Weis 1991). A Hansatech Plant Efficiency Analyzer was used. All measurements were performed in the dark by exposing leaves for $5 \mathrm{~s}$ to a maximum light intensity of $3,000 \mu \mathrm{mol} \mathrm{m} \mathrm{m}^{-2} \mathrm{~s}^{-1} . \Delta^{\mathrm{Fv}} / \mathrm{Fm}$ values were determined by deducting the $\mathrm{Fv}_{\mathrm{Fm}}$ value of a leaf 24 hpi from the pre-infiltration $\mathrm{Fv} / \mathrm{Fm}$ value of the same leaf. All chlorophyll fluorescence measurements were done in triplicate for each infiltrated leaf. Three leaves were infiltrated for each experiment, bringing the total number of chlorophyll fluorescence measurements to nine for each experiment.

\section{Statistical analysis.}

All statistical analysis was done by one-way analysis of variance using the STATISTICA 7 (StatSoft Inc, Tulsa, OK, U.S.A.) software package at $95 \%$ confidence intervals.

\section{Plasmon resonance experiments.}

Immobilization of VvPGIP on sensor chip. A single flow cell of a CM5 sensor chip was equilibrated at $25^{\circ} \mathrm{C}$ with $\mathrm{HBS}$ buffer (10 mM Hepes, $150 \mathrm{mM} \mathrm{NaCl}, 3.4 \mathrm{mM}$ EDTA, 0.05\% $\mathrm{P} 20, \mathrm{pH}$ 7.4) followed by the automated immobilization of purified VvPGIP1. During the automated immobilization, equal volumes of $0.1 \mathrm{M} N$-hydroxy succinimide and $0.1 \mathrm{M} \mathrm{1-}$ ethyl-3-(3-dimethylaminopropyl) carbodiimide hydrochloride were mixed by the BIAcore system and eluted over the surface of the sensor chip to activate the carboxymethylated dextran. Subsequently, $65 \mu \mathrm{l}$ of VvPGIP1 $\left(20 \mu \mathrm{g} \mu \mathrm{l}^{-1}\right)$ was injected over the activated surface at a flow rate of $5 \mu \mathrm{min}^{-1}$ and the remaining active carboxyl groups were deactivated with an injection of $1 \mathrm{M}$ ethanolamine. This was followed by a 1-h wash with HBS buffer to ensure a stable base line. As a control, this procedure was repeated in a separate flow cell without the immobilization of VvPGIP1. Approximately 5,400 resonance units (RU) of VvPGIP1 were coupled.

Binding assays on the BIAcore. All experiments were carried out at $25^{\circ} \mathrm{C}$ with a constant flow rate of running buffer (10 mM sodium acetate, $150 \mathrm{mM} \mathrm{NH} \mathrm{N}_{4} \mathrm{Cl}, 0.005 \% \mathrm{P} 2 \mathrm{O}, \mathrm{pH}$ range 4.2, 4.75, and 5.0) at $10 \mu \mathrm{min}^{-1}$. Purified ligand (AnPGI and BcPG2) at a final concentration of approximately $10 \mu \mathrm{g} \mathrm{ml}^{-1}$ in running buffer was injected over the immobilized VvPGIP1 and binding was evaluated qualitatively. Association, dissociation, and regeneration phases were followed in real time as a change in signal expressed in RU. The resulting sensorgrams used for binding analysis were obtained by subtracting the flow cell sensorgram from the control flow cell sensorgram. All steps described were fully automated and carried out by the BIAcore system's robotics. The 1,000 RU represents protein bound to the sensor chip surface at approximately $1 \mathrm{ng} \mathrm{mm}^{-2}$. All BIAcore binding experiments were repeated with an independently constructed sensor chip.
High-performance anion exchange chromatography with amperometric detection.

The OGA profile generated by BcPG2 from homogalacturonan was obtained by anion exchange chromatography using a Metrohm Peak high-performance liquid chromatography with a Bioscan (model 817) pulsed amperometric detector and a Dionex CarboPAC PA1 column coupled to a Dionex amperometric detector as described by Cook and associates (1999). PGA $(0.025 \%)$ was used as substrate and the reaction was allowed to continue for $1 \mathrm{~h}$ at room temperature in $20 \mathrm{mM}$ sodium acetate, $\mathrm{pH}$ 4.0.

\section{ACKNOWLEDGMENTS}

The authors would like to thank A. Jones for excellent technical assistance and A. de Beer for providing the VvAMP1 construct. A. ten Have is acknowledged for design and construction of the expression vectors pAT1 and pAT2. This work was supported by grants from the South African Wine Industry (Winetech), the National Research Foundation of South Africa (NRF), by the Dutch Technology Foundation STW, applied science division of NWO and the technology program of the Ministry of Economic Affairs (project WGC.5034), the United States Department of Energy (DOE) (DE-FG02-96ER20221), and the DOE-funded Center for Plant and Microbial Complex Carbohydrates (DE-FG02-93ER20097).

\section{LITERATURE CITED}

Agüero, C. B., Uratsu, S. L., Greve, C., Powell, A. L. T., Labavitch, J. M., Meredith, C. P., and Dandekar, A. M. 2005. Evaluation of tolerance to Pierce's disease and Botrytis in transgenic plants of Vitis vinifera L. expressing the pear PGIP gene. Mol. Plant Pathol. 6:43-51.

Bergmann, C. W., Ito, Y., Singer, D., Albersheim, P., Darvill, A. G., Benhamou, N., Nuss, L., Salvi, G., Cervone, F., and De Lorenzo, G. 1994. Polygalacturonase-inhibiting protein accumulates in Phaseolus vulgaris L. in response to wounding, elicitors and fungal infection. Plant J. 5:625-634.

Bishop, J. G. 2005 Directed mutagenesis confirms the functional importance of positively selected sites in polygalacturonase-inhibitor protein. Mol. Biol. Evol. 22:1531-1534.

Boudart, G., Charpentier, M., Lafitte, C., Martinez, Y., Jauneau, A., Gaulin, E., Esquerré-Tugayé M.-T., and Dumas, B. 2003. Elicitor activity of a fungal endopolygalacturonase in tobacco requires a functional catalytic site and cell wall localization. Plant Physiol. 131:93-101.

Bradford, M. M. 1976. A rapid and sensitive method for the quantification of microgram quantities of protein utilizing the principle of protein-dye binding. Anal. Biochem. 72:248-254.

Capodicasa, C., Vairo, D., Zabotina, O., McCartney, L., Caprari, C., Mattei, B., Manfredini, C., Aracri, B., Benen, J., Knox, J. P., De Lorenzo, G., and Cervone, F. 2004. Targeted modification of homogalacturonan by transgenic expression of a fungal polygalacturonase alters plant growth Plant Physiol. 135:1294-1304.

Cervone, F., De Lorenzo, G., Degrà, L., Salvi, G., and Bergami, M. 1987. Purification and characterization of a polygalacturonase-inhibiting protein from Phaseolus vulgaris L. Plant Physiol. 85:631-637.

Cervone, F., Hahn, M. G., De Lorenzo, G., Darvill, A., and Albersheim, P. 1989. Host pathogen interactions XXXIII: A plant protein converts a fungal pathogenesis factor into an elicitor of plant defense responses. Plant Physiol. 90:542-548.

Chapple, C., and Carpita, N. 1998. Plant cell walls as targets for biotechnology. Curr. Opin. Plant Biol. 1:179-185.

Cook, B. J., Clay, R. P., Bergmann, C. W., Albersheim, P., and Darvill, A. 1999. Fungal polygalacturonases exhibit different substrate degradation patterns and differ in their susceptibilities to polygalacturonase inhibiting proteins. Mol. Plant-Microbe Interact. 12:703-711.

De Lorenzo, G., and Ferrari, S. 2002. Polygalacturonase-inhibiting proteins in defense against phytopathogenic fungi. Curr. Opin. Plant Biol. 5:295-299.

De Lorenzo, G., D’Ovidio, R., and Cervone, F. 2001. The role of polygalacturonase-inhibiting proteins (PGIPs) in defense against pathogenic fungi. Annu. Rev. Phytopathol. 39:313-335.

Desiderio, A., Aracri, B., Leckie, F., Mattei, B., Salvi, G., Tigelaar, H., Van Roekel, J. S., Baulcombe, D. C., Melchers, L. S., De Lorenzo, G., and Cervone, F. 1997. Polygalacturonase-inhibiting proteins (PGIPs) with different specificities are expressed in Phaseolus vulgaris. Mol. PlantMicrobe Interact. 10:852-860.

Devoto, A., Leckie, F., Lupotto, E., Cervone, F., and De Lorenzo, G. 1998. 
The promoter of a gene encoding a polygalacturonase-inhibiting protein of Phaseolus vulgaris L. is activated by wounding but not by elicitors or pathogen infection. Planta 205:165-174.

de Wit, P. J. G. M., and Spikman, G. 1982. Evidence for the occurrence of race and cultivar-specific elicitors of necrosis in intercellular fluids of compatible interactions of Cladosporium fulvum and tomato. Physiol. Plant Pathol. 21:1-11.

Favaron, F., D’Ovidio, R. D., Porceddu, E., and Alghisi, P. 1994. Purification and molecular characterization of a soybean polygalacturonaseinhibiting protein. Planta 195:80-87.

Federici, L., Caprari, C., Mattei, B., Savino, C., Di Matteo, A., De Lorenzo, G., Cervone, F., and Tsernoglou, D. 2001. Structural requirements of endopolygalacturonase for the interaction with PGIP (polygalacturonase-inhibiting protein). Proc. Natl. Acad. Sci. U.S.A. 98:1342513430.

Ferrari, S., Vairo, D., Ausubel, F. M., Cervone, F., and De Lorenzo, G. 2003. Tandemly duplicated Arabidopsis genes that encode polygalacturonase-inhibiting proteins are regulated coordinately by different signal transduction pathways in response to fungal infection. Plant Cell 15:93106.

Gleave, A. P. 1992. A versatile binary vector system with a T-DNA organisational structure conducive to efficient integration of cloned DNA into the plant genome. Plant Mol. Biol. 20:1203-1207.

Honée, G., Buitink, J., Jabs, T., De Kloe, J., Sijbolts, F., Apothekers, M., Weide, R., Sijen, T., Stuiver, M., and de Wit, P. J. G. M. 1998. Induction of defence-related responses in Cf9 tomato cells by the AVR9 elicitor peptide of Cladosporium fulvum is developmentally regulated. Plant Physiol. 117:809-820.

Hood, E. A., Gelvin, S. B., Melchers, L. S., and Hoekema, A. 1993. New Agrobacterium helper plasmids for gene transfer to plants. Transgenic Res. 2:208-218.

Joubert, D. A., Slaughter, A. R., Kemp, G., Becker, V. W. J., Krooshof, G. H., Bergmann, C., Benen, J., Pretorius, I. S., and Vivier, M. A. 2006. The grapevine polygalacturonase-inhibiting protein (VvPGIP1) reduces Botrytis cinerea susceptibility in transgenic tobacco and differentially inhibits fungal polygalacturonases. Transgenic Res. 15:687-702.

Kars, I., and van Kan, J. A. L. 2004. Extracellular enzymes and metabolites involved in pathogenesis of Botrytis. Pages 99-118 in: Botrytis: Biology, Pathology and Control. Y. Elad, B. Williamson, P. Tudzynski, and N. Nelen, eds. Kluwer Academic Publishers, Dordrecht, The Netherlands.

Kars, I., Krooshof, G. H., Wagemakers, L., Joosten, R., Benen, J. A. E., and van Kan, J. A. L. 2005. Necrotizing activity of five Botrytis cinerea endopolygalacturonases produced in Pichia pastoris. Plant J. 43:213-225.

Kemp, G., Stanton, L., Bergmann, C. W., Clay, R. P., Albersheim, P., and Darvill, A. 2004. Polygalacturonase-inhibiting proteins can function as activators of polygalacturonase. Mol. Plant-Microbe Interact. 17:888-894.

King, D., Bergmann, C., Orlando, R., Benen, J. A., Kester, H. C., and Visser J. 2002. Use of amide exchange mass spectrometry to study conformational changes within the endopolygalacturonase II-homogalacturonanpolygalacturonase inhibiting protein system. Biochemistry 41:1022510233.

Komjanc, M., Festi, S., Rizzotti, L., Cattivelli, L., Cervone, F., and De Lorenzo, G. 1999. A leucine-rich repeat receptor-like protein kinase $(\mathrm{LRPKm} 1)$ gene is induced in Malus $\times$ domestica by Venturia inaequalis infection and salicylic acid treatment. Plant Mol. Biol. 40:945-957.

Krause, G. H., and Weis, E. 1991. Chlorophyll fluorescence and photosynthesis: The basics. Annu. Rev. Plant Physiol. Plant Mol. Biol. 42:313-349.

Leckie, F., Mattei, B., Capodicasa, C., Hemmings, A., Nuss, L., Aracri, B., De Lorenzo, G., and Cervone, F. 1999. The specificity of polygalacturonase-inhibiting protein (PGIP): A single amino acid substitution in the solvent-exposed beta-strand/beta-turn region of the leucine-rich repeats (LRRs) confers a new recognition capability. EMBO (Eur. Mol. Biol. Organ.) J. 18:2352-2363.

Mahalingam, R., Wang, G., and Knap, H. T. 1999. Polygalacturonase and polygalacturonase inhibitor protein: Gene isolation and transcription in
Glycine max-Heterodera glycines interactions. Mol. Plant-Microbe Interact. 12:490-498.

Poinssot, B., Vandelle, E., Bentéjac, M., Adrian, M., Levis, C., Brygoo, Y., Garin, J., Sicilia, F., Coutos-Thévenot, P., and Pugin, A. 2003. The endopolygalacturonase 1 from Botrytis cinerea activates grapevine defense reactions unrelated to its enzyme activity. Mol. Plant-Microbe Interact. 16:553-564

Powell, A. L. T., Van Kan, J., Ten Have, A., Visser, J., Greve, L. C., Bennett, A. B., and Labavitch, J. M. 2000. Transgenic expression of pear PGIP in tomato limits fungal colonization. Mol. Plant-Microbe Interact. 9:942-950.

Reymond, P., Grunberger, S., Paul, K., Muller, M., and Farmer, E. E. 1995. Oligogalacturonide defense signals in plants: Large fragments interact with the plasma membrane in vitro. Proc. Natl. Acad. Sci. U.S.A. 92:4145-4149.

Rogers, S. G., Klee, H. J., Horsch, R. B., and Frayley, R. T. 1987. Improved vectors for plant transformation: Expression cassette vectors and new selectable markers. Methods Enzymol. 153:253-277.

Spadoni, S., Zabotina, O., Di Matteo, A.., Dalgaard Mikkelsen, J., Cervone, F., De Lorenzo, G., Mattei, B., and Bellincampi, D. 2006. Polygalacturonase-inhibiting protein interacts with pectin through a binding site formed by four clustered residues of arginine and lysine. Plant Physiol. 141:557-563.

Stotz, H. U., Contos, J. J. A., Powell, A. L. T., Bennett, A. B., and Labavitch, J. M. 1994. Structure and expression of an inhibitor of fungal polygalacturonases from tomato. Plant Mol. Biol. 25:607-617.

Stotz, H. U., Bishop, J. G., Bergmann, C. W., Koch, M., Albersheim, P., Darvill, A. G., and Labavitch, J. M. 2000. Identification of target amino acids that effect interactions of fungal polygalacturonases and their plant inhibitors. Physiol. Mol. Plant Pathol. 56:117-130.

Taylor, R. J., and Secor, G. A. 1988. An improved diffusion assay for quantifying the polygalacturonase content of Erwinia culture filtrates. Phytopathology 78:1101-1103.

ten Have, A., Mulder, W., Visser, J., and van Kan, J. A. L. 1998. The endopolygalacturonase gene Bcpgl is required for full virulence of Botrytis cinerea. Mol. Plant-Microbe Interact. 11:1009-1016.

ten Have, A., Oude Brueil, W., Wubben, J., Visser, J., and van Kan, J. A. L. 2001. Botrytis cinerea endopolygalacturonase genes are differentially expressed in various plant tissues. Fungal Genet. Biol. 33:97-105.

ten Have, A., Tenberge, K. B., Benen, J. A. E., Tudzynski, P., Visser, J., and van Kan, J. A. L. 2002. The contribution of the cell wall degrading enzymes to pathogenesis of fungal plant pathogens. Pages 341-358 in The Mycota XI, Agricultural Applications. F. Kempken, ed. SpringerVerlag, Berlin.

van den Burg, H. A. Harrison, S. J. Joosten, M. H. A. J. Vervoort, J., and de Wit, P. J. G. M. 2006. Cladosporium fulvum Avr4 protects fungal cell walls against hydrolysis by plant chitinases accumulating during infection. Mol. Plant-Microbe Interact. 19:1420-1430.

van der Hoorn, R. A., Laurent, F., Roth, R., and de Wit, P. J. G. M. 2000 Agroinfiltration is a versatile tool that facilitates comparative analyses of Avr9/Cf-9-induced necrosis. Mol. Plant-Microbe Interact. 13:439446.

Wroblewski, T., Tomczak, A., and Michelmore, R. W. 2005. Optimization of Agrobacterium-mediated transient assays of gene expression in lettuce, tomato and Arabidopsis. Plant Biotechnol. 3:259-273.

Wubben, J. P., Mulder, W., ten Have, A., van Kan, J. A. L., and Visser, J. 1999. Cloning and partial characterisation of endopolygalacturonase genes from Botrytis cinerea. Appl. Environ. Microbiol. 65:1596-1602.

York, W. S., Darvill, A. G., McNiel, M., Stevenson, T. T., and Albersheim, P. 1985. Isolation and characterization of plant cell walls and plant cell wall components. Methods Enzymol. 118:3-40.

\section{AUTHOR-RECOMMENDED INTERNET RESOURCE}

The Gene Index Project website: compbio.dfci.harvard.edu/tgi/cgi-bin/tgi/Blast/index.cgi 